designed filter. Such signals are normally drowned out by a blaze of infrared emissions of wavelength 1,000-1,800 nanometres coming from hydroxyl chemicals in Earth's upper atmosphere.

The filter, developed by Joss Bland-Hawthorn at the University of Sydney, Australia, and his colleagues, combines two technologies: Bragg gratings, which are fibre-optic cables with unevenly spaced notches that suppress and reflect up to 400 hydroxyl spectral lines; and a converter that funnels the light from the sky into the grating as a single ray.

Tests at an observatory over three evenings showed that the filter blocked out most of the brightest emissions with wavelengths between 1,440 and 1,630 nanometres. Although a still a prototype, the device could be used with 8-metre and future 30-metre telescopes, the authors say. Nature Commun. 2, 581 (2011)

\section{BIOELECTRONICS}

\section{Recharge through the skin}

Replacing the batteries of implanted medical devices such as pacemakers usually requires surgery. An invention (pictured) by Eijiro Miyako at the National Institute of Advanced Industrial Science and Technology in Ikeda, Japan, and his colleagues could, in theory, provide a noninvasive way to recharge such devices. The authors have built an implantable converter that generates electric current when hit with laser light that is beamed through the skin.

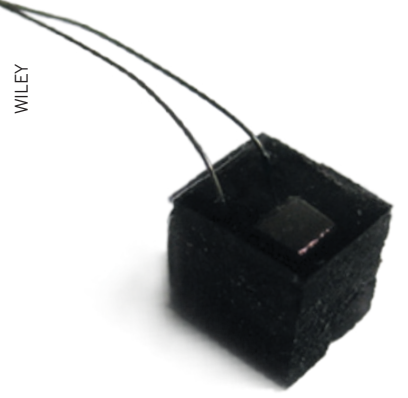

$1 \mathrm{~cm}$
The device consists of carbon nanotubes - which heat up when exposed to laser light — wrapped in a polymer and dispersed in silicone. The heat warms one side of the converter more than the other, and the flow of heat to the cooler side generates an electric voltage.

The researchers show that, when irradiated with laser light, their device can electrically stimulate a zebrafish heart, and can generate a voltage while implanted in a rat.

Angew. Chem. Int. Edn http://dx.doi.org/10.1002/ anie.201106136 (2011)

\section{EVOLUTION AND DEVELOPMENT}

\section{How the brain became human}

Humans' evolution of big brains and unique cognitive abilities may be down to key regulators that control gene expression during development.

Philipp Khaitovich and Svante Pääbo at the Max Planck Institute for Evolutionary Anthropology in Leipzig, Germany, and their colleagues compared gene-expression patterns in the brains of dozens of humans, chimpanzees and rhesus macaques of different ages. Relative to those of chimps and macaques, human brains showed many more differences in gene-expression patterns as newborns developed into adults, particularly in a region involved in cognition called the prefrontal cortex (PFC). Genes that encode microRNAs, which regulate the activity of many other genes, were among those whose developmental expression patterns varied most between the PFCs of humans and other primates.

The authors suggest that a small number of microRNAs and proteins controlling brain development could have driven the evolution of the human brain.

PLoS Biol. 9, e1001214 (2011)

COMMUNITY CHOICE

The most viewed papers in science

\title{
The brain's nutrient sensor
}

\section{HIGHLY READ \\ on www.cell.com in November}

Certain brain cells can respond not only to changing glucose levels, but also to mixtures of amino acids - the building blocks of proteins. This suggests that the brain can sense the body's nutrient status in addition to its energy needs.

Denis Burdakov at the University of Cambridge, UK, and his colleagues looked at cells in the brain's hypothalamus called orexin/hypocretin neurons, which regulate energy balance and feeding. Working with mice, they found that these cells were activated both in vitro and in vivo when exposed to nutritionally relevant amino-acid mixtures.

Glucose normally suppresses the activity of these neurons, but when the researchers exposed the cells to both glucose and amino acids, the amino acids excited the neurons and blocked the effect of glucose. The authors suggest that this boosts the signal from amino acids, which are typically at lower concentrations in the brain than glucose.

Neuron 72, 616-629 (2011)

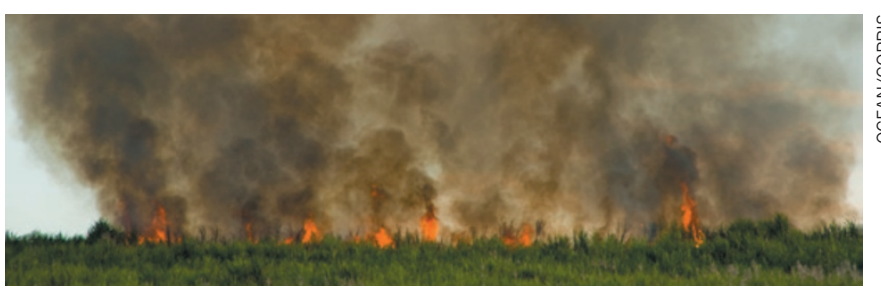

\section{Sugar-cane biofuel fouls air}

Brazil has rapidly become the world's biggest producer of ethanol - an alternative to petroleum-based fuel - from sugar cane. The greenhousegas emissions created during sugar-cane ethanol production are lower than those associated with the creation of other biofuels, but a study shows that the process generates up to seven times more air pollutants than previously estimated from remote-sensing data.

Elliott Campbell at the University of California, Merced, and his colleagues used agricultural survey data from Brazil to calculate emissions of various air pollutants, such as sulphur dioxide and black carbon, from the entire production cycle of sugar-cane ethanol in 2000-08. A major source of emissions is the burning of sugarcane fields before harvest (pictured). The authors' estimates of emissions from just this burning phase were 1.5-7.3 times higher than those from satellite-based methods. Altogether, the production of sugar-cane ethanol generated more pollutants than petrol or diesel production.

The authors say that even in regions where burning has been scaled back, pollutant emissions continue to grow because of the increase in sugar-cane production in Brazil.

Nature Climate Change http://dx.doi.org/10.1038/ nclimate1325 (2011)

\section{$\rightarrow$ NATURE.COM}

For the latest research published by Naturevisit:

www.nature.com/latestresearch 